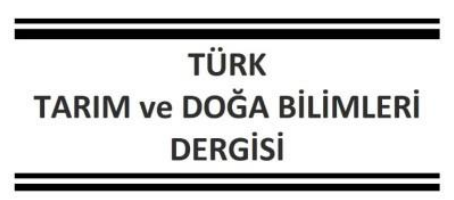

\title{
Araştırma Makalesi \\ Aras Vadisi Cleonini ve Tanymecini (Coleoptera: Curculionidae) Türleri Üzerinde Biyolojik ve Biyocoğrafik Notlar
}

www.dergipark.gov.tr/turkjans

\author{
Neslihan GÜLTEKIN ${ }^{1}$ Celalettin GÖZÜAÇIK ${ }^{1}$ Ersin AYKUT ${ }^{1}$ Levent GÜLTEKIN² ${ }^{2}$ Boris A. KOROTYAEV ${ }^{3}$ \\ ${ }^{1}$ Iğdır Üniversitesi, Ziraat Fakültesi, Bitki Koruma Bölümü, 76000, Iğdır, Türkiye \\ ${ }^{2}$ Biyoçeşitlilik Uygulama ve Araştırma Merkezi, Atatürk Üniversitesi, 25240, Erzurum, Türkiye \\ ${ }^{3}$ Zoological Institute, Russian Academy of Sciences, Universitetskaya nab. 1, 199034, St. Petersburg, Rusya \\ *Sorumlu Yazar: nesgultekin@gmail.com
}

Geliş Tarihi: 01.05.2020, Düzeltme Geliş Tarihi: 06.01.2021, Kabul Tarihi: 10.01.2021

\section{$\overline{O ̈ z}$}

Aras vadisinde Cleonini ve Tanymecini tribüsüne ait Cleonis pigra (Scopoli, 1763), Conorhynchus kindermanni Faust,1904, Bothynoderes affinis (Schrank, 1781), Pachycerus segnis (Germar, 1824), Maximus strabus (Gyllenhal, 1834), Asproparthenis punctiventris (Germar, 1824), A. steveni (Faust, 1892), A. omeri Korotyaev, N. Gültekin \& L. Gültekin, 2020, Temnorhinus nasutus (Hochhuth, 1847), T. hololeucus (Pallas, 1781), Entymetopus lineolatus Motschulsky, 1860, E. limis (Ménétriés, 1849), Esamus mnischekii (Hochhuth, 1851), Tanymecus dilaticollis Gyllenhal, 1834 ve T. tenuis Reitter, 1903 türleri belirlenmiştir. Asproparthenis steveni, B. affinis, E. lineolatus, E. limis ve Temnorhinus nasutus türleri için yeni biyolojik bulgular ve konukçu bitkiler tespit edilmiştir. Bassia hirsuta bitkisi B. affinis, M. strabus, Entymetopus lineolatus, E. limis ve Tanymecus tenuis için yeni bir konukçudur. Suaeda confusa bitkisi T. nasutus ve Atriplex micrantha bitkisi T. hololeucus için yeni konukçulardır. İlk bilimsel veri olarak, Entymetopus lineolatus ve A. steveni pupa dönemlerinin topraktan hazırlanmış bir kapsül içerisinde ve konukçu bitkinin altında toprak içerisinde bulunmuştur. En ilginç bulgulardan birisi de Temnorhinus hololeucus'un uçma kabiliyetinin olduğu, çöl habitatında konukçu bitkiye ulaşmak için uçuş yapabilmesidir. Entymetopus limis, Esamus Chevrolat, 1880 cinsi ve Esamus mnischekii (Hochhuth, 1851) Türkiye faunası için yeni kayıttır.

Anahtar kelimeler: Cleonini, Tanymecini, konukçu bitki, yeni biyolojik bulgular, Esamus mnischekii, yeni kayıt, Aras vadisi

Biological and Biogeographical Notes on Cleonini and Tanymecini (Coleoptera: Curculionidae) Species in the Aras Valley

\section{Abstract}

Weevils of the tribes Cleonini and Tanymecini, Cleonis pigra (Scopoli, 1763), Conorhynchus kindermanni Faust,1904, Bothynoderes affinis (Schrank, 1781), Pachycerus segnis (Germar, 1824), Maximus strabus (Gyllenhal, 1834), Asproparthenis punctiventris (Germar, 1824), A. steveni (Faust, 1892), A. omeri Korotyaev, N. Gültekin \& L. Gültekin, 2020, Temnorhinus hololeucus (Pallas, 1781), T. nasutus (Hochhuth, 1847), Entymetopus lineolatus Motschulsky, 1860, E. limis (Ménétriés, 1849), Esamus mnischekii (Hochhuth, 1851), Tanymecus dilaticollis Gyllenhal, 1834 and T. tenuis Reitter, 1903 were investigated in the Aras River valley. New biological data and new host plants are reported for A. steveni, B. affinis, Entymetopus lineolatus, E. limis and Temnorhinus nasutus. Bassia hirsuta is a new host plant for B. affinis, M. strabus, Entymetopu lineolatus, E. limis and Tanymecus tenuis. Suaeda confusa is a new food plant for Temnorhinus nasutus, and Atriplex micrantha, for Temnorhinus hololeucus. Pupae of Entymetopus lineolatus and A. steveni are detected in a soil case under their host plants which are the first data on the localisation of pupal stage of these species. One of the most interesting findings is that $T$. hololeucus has the ability to flight to reach host plants in desert habitat. Entymetopus limis, genus Esamus Chevrolat, 1880 and Esamus mnischekii (Hochhuth, 1851) are new records for the fauna of Turkey.

Key words: Cleonini, Tanymecini, host plant, new biological findings, Esamus mnischekii, new record, Aras valley 


\section{Giriş}

Curculionoidea (Insecta: Coleoptera) dünyada yaşayan tüm organizmaların en zengin grubu olarak bilinmekte olup (Oberprieler ve ark., 2007), türlerin tamamına yakını fitofagdır (Korotyaev, 2000). Cleonini türleri Holoarktik Bölge'de en zengin tür çeşitliğine sahiptir ve coğrafik yayılışları Afrika ve Madagaskar'a kadar uzanmaktadır (Arzanov ve Grebennikov, 2017). Eski Sovyetler Birliği 245 türle dünyanın en zengin Cleonini faunasına sahiptir (Ter-Minassian, 1988). Nearktik Bölge 35 türle temsil edilmektedir (Anderson, 1987). Palearktik bölgeden ise 480 civarında tür belirtilmektedir (Meregalli ve Fremuth, 2013). Anadolu Cleonini faunası ise 31 türle temsil edilmektedir (Meregalli ve Fremuth, 2013; Gültekin, 2018). Bu gruba ait türlerin çoğu yaşam alanı olarak genellikle kurakçıl habitatları tercih etmektedirler (Anderson, 1987; Volovnik, 2010; Meregalli, 2014; Stejskal ve Trnka, 2014). Larvalar beslenmek için çoğunlukla bitkilerin kökboğazı ve köklerini yaşam alanı olarak tercih etmekte, bitki dokusu içerisinde (Trnka ve ark., 2015), gal oluşturarak (Volovnik, 2010) veya toprakta serbest olarak hareket ederek kök aksamı ile beslenirler. $\mathrm{Bu}$ zamana kadar yapılan çalışmalarda 14 türün şekerpancarı zararlısı olarak, özellikle de bazı Asproparthenis Gozis türlerinin (Asproparthenis punctiventris $=$ Bothynoderes punctiventris) tahripkar olduğu belirtilmektedir (Lukjanovitsh, 1958; Ter-Minassian, 1958, 1988; Tóth ve ark., 2007; EPPO, 2015; Lemic ve ark., 2016; Arzanov ve Grebennikov 2017). Bu grup böcekler spesifik beslenme özelliklerine bağlı olarak yabancı otların biyolojik mücadelesinde de önem arz etmektedir (Stinson ve ark., 1994; Story ve ark., 2006; Gültekin ve ark., 2019).

Tanymecini (Curculionidae) türleri yayılış alanı olarak daha çok doğu Palearktik bölgeyi tercih etmektedir (Alonso-Zarazaga ve ark., 2017). Mevcut katalog bilgisine göre Türkiye'de 15 Tanymecini türü yayılış göstermekte (AlonsoZarazaga ve ark., 2017) ve bunlardan iki tür Tanymecus dilaticollis Gyllenhal, 1834 and Megamecus shevketi Marshall ve Lodos, 1979 sırasıyla mısır ve bağlarda tarımsal zararlı olarak bilinmektedir (Marshall ve Lodos, 1979; Güllü ve Sertkaya, 2011; Gözüaçık, 2019). Mısır maymuncuğu T. dilaticollis Avrupa, Anadolu, Iran, Rusya ve Kafkasya'da mısırın fide döneminde en önemli zararlısı olarak bilinir (Davidian, 2019).

Aras vadisi olarak adlandırılan alan, Aras nehri boyunca uzanmaktadır. Aras nehri Bingöl Dağlarından kaynaklanarak, Erzurum, Kars, Iğdır illerinden geçerek Ermenistan, Nahcivan ve Azerbaycan güzergahı içerisinde Kura nehri birleşerek Hazar Denizi'ne ulaşmaktadır.
Biyocoğrafik ve biyoçeşitlilik yönden oldukça ilginç ve zengin olan Aras vadisi, Anadolu, Transkafkasya, İran ve Orta Asya arasında bir koridor niteliğindedir.

\section{Materyal ve Metot}

Araştırma bölgesi Aras nehir vadisi boyunca Kağızman'ın doğu sınırlarından başlayıp, Tuzluca, Iğdır, Karakoyunlu ve Aralık ilçelerini kapsayacak şekilde Iğdır ili kapsamında farklı tipte habitatlar seçilerek atrap, aspirator, pitfal tuzağı ve elek kullanılarak Cleonini ve Tanymecini tribüslerine ait böcek örnekleri toplanmıştır. İnceleme yapılan her bir lokaliteye ayrı bir numara verilerek GPS ile coğrafik veriler (koordinat, rakım) kayıt edilmiştir (Çizelge 1). Konukçu olarak tespit edilen bitkilerin herbaryumu yapılmış ve konukçu bitkilere ait dijital fotoğraflar çekilerek kayıt altına alınmıştır. Doğadan toplanılan ergin dönem örnekler etil asetatlı tüplerde öldürüldükten sonra her bir coğrafik lokasyondan toplanmış örnekler ayrı olacak şekilde pamuklu zarflar üzerine dizilmiş (Şekil 1), etiket bilgisi üstüne kapatılan kağıt üzerine yazılarak muhafaza altına alınmıştır. Genç biyolojik dönemler etil alkol içeren tüplerde etiketlenerek buzdolabında muhafaza edilmektedir. Örneklerin doğada yaşamak için tercih ettikleri ekosistemler ve biyolojik dönemlerin mikrohabitatları tespit edilmeye çalışılmış ve dijital fotoğrafları çekilmiştir. Toprak içerisinde yaşayan ergin öncesi dönemler (larva ve pupa), doğal ortamlarına benzer şekilde içerisinde bitki kökleri ve kumlu toprak içeren kaplar kullanılarak laboratuvarda kültüre alınarak ergin olmaları sağlanmaya çalışılmıştır. Toplanan ergin örnekler iğnelenip ya da karton kağıtlar üzerine yapıştırılarak koleksiyon haline getirilmiştir. Hazırlanan koleksiyon taksonomik yönden incelenerek tür düzeyinde teşhis edilmiştir.

\section{Bulgular ve Tartışma}

Aras vadisi Cleonini ve Tanymecini tür çeşitliliğini belirlenebilmesi için 2019 yılı MayısAğustos ayları arasında toplam 15 lokasyonda (Çizelge 1) sörveyler yapılarak inceleme, örnekleme, konukçu bitkiler ve biyolojik özellikler üzerinde araştırmalar gerçekleştirilmiştir.

Araştırma sonuçlarına göre 2019 yaz sezonunda Aras vadisi boyunca Kağızman (Kars) ve Iğdır ilinde Cleonini tribüsüse ait Cleonis pigra (Scopoli, 1763), Conorhynchus kindermanni Faust,1904, Bothyoderes affinis (Schrank, 1781), Pachycerus segnis (Germar, 1824), Maximus strabus (Gyllenhal, 1834), Asproparthenis punctiventris (Germar, 1824), A. steveni (Faust, 1892), A. omeri Korotyaev, N. Gültekin \& L. Gültekin, 2020, Temnorhinus hololeucus (Pallas, 
1781), T. nasutus (Hochhuth, 1847), Entymetopus lineolatus Motschulsky, 1860, E. limis (Ménétriés, 1849) ve Tanymecini tribüsüne ait Esamus mnischekii (Hochhuth, 1851), Tanymecus dilaticollis Gyllenhal, 1834 ve T. tenuis Reitter, 1903 türleri tespit edilmiştir. Tespit edilen türlerin Aras vadisinde beslendiği konukçu bitkiler liste halinde aşağıda Çizelge 2 'de sunulmuştur.

Çizelge 1. Aras vadisinde 2019 yılında doğa araştırmaları yapılan lokasyonlar

\begin{tabular}{|c|c|c|c|c|}
\hline $\begin{array}{l}\text { Lokasyon } \\
\text { Numarası }\end{array}$ & Coğrafik Bilgi & Tarih & Rakım & Coğrafik Koordinat \\
\hline TR19-01 & Iğdır, Aralık, Yukarıçamurlu & 01.05 .2019 & $820 \mathrm{~m}$ & $\begin{array}{l}39^{\circ} 56^{\prime} 6.22^{\prime \prime K} \\
44^{\circ} 23^{\prime} 42.63^{\prime \prime D}\end{array}$ \\
\hline TR19-02 & Iğdır, 2 km Melekli'nin doğusu & 07.05 .2019 & $853 \mathrm{~m}$ & $\begin{array}{l}39^{\circ} 56^{\prime} 16.56^{\prime \prime} \mathrm{K} \\
44^{\circ} 6^{\prime} 35.39 " \mathrm{D}\end{array}$ \\
\hline TR19-03 & Iğdır, 8 km Aralık'ın batısı & 07.05 .2019 & $854 \mathrm{~m}$ & $\begin{array}{l}39^{\circ} 54^{\prime} 52.97 " \mathrm{~K} \\
44^{\circ} 22^{\prime} 13.84^{\prime \prime} \mathrm{D}\end{array}$ \\
\hline TR19-04 & $\begin{array}{l}\text { Iğdır, Tuzluca, Turabi köyünün 3-4 km güney } \\
\text { batısı }\end{array}$ & 14.05.2019 & $1017 \mathrm{~m}$ & $\begin{array}{l}40^{\circ} 3 ' 24.39 " \mathrm{~K} \\
43^{\circ} 44^{\prime} 34.82^{\prime \prime D}\end{array}$ \\
\hline TR19-05 & Iğdır, Tuzluca'nın 3 km doğusu & 14.05.2019 & $1020 \mathrm{~m}$ & $\begin{array}{l}40^{\circ} 2^{\prime} 47.32^{\prime \prime K} \\
43^{\circ} 42^{\prime} 59.21^{\prime \prime}\end{array}$ \\
\hline TR19-06 & Iğdır, 6 km Aralık'ın batısı & 18.06.2019 & $824 \mathrm{~m}$ & $\begin{array}{l}39^{\circ} 55^{\prime} 46.53^{\prime \prime K} \\
44^{\circ} 23^{\prime} 51.80^{\prime \prime D}\end{array}$ \\
\hline TR19-07 & Iğdır, 5 km Aralık'ın doğusu & 18.06.2019 & $820 \mathrm{~m}$ & $\begin{array}{l}39^{\circ} 47^{\prime} 54.30^{\prime \prime} \mathrm{K} \\
44^{\circ} 35^{\prime} 20.98^{\prime \prime} \mathrm{D}\end{array}$ \\
\hline TR19-08 & Iğdır, Aralık, Hacıağa köyünün 2 km güneyi & 18.06.2019 & $817 \mathrm{~m}$ & $\begin{array}{l}39^{\circ} 54^{\prime} 15.90^{\prime \prime} \mathrm{K} \\
44^{\circ} 30^{\prime} 35.02^{\prime \prime} \mathrm{D}\end{array}$ \\
\hline TR19-09 & $\begin{array}{l}\text { Iğdır, Tuzluca, Turabi köyünün 3-4 km güney } \\
\text { batısı }\end{array}$ & 19.06.2019 & $1017 \mathrm{~m}$ & $\begin{array}{l}40^{\circ} 3 ' 24.39 " \mathrm{~K} \\
43^{\circ} 44^{\prime} 34.82^{\prime \prime D}\end{array}$ \\
\hline TR19-10 & Iğdır-Kars il sınırı, Donandı köyünün 3-4 km batısı & 09.07.2019 & $1070 \mathrm{~m}$ & $\begin{array}{l}40^{\circ} 7 ' 37.67 " K \\
43^{\circ} 24^{\prime} 5.44^{\prime \prime D}\end{array}$ \\
\hline TR19-11 & $\begin{array}{l}\text { Iğdır, Tuzluca, Turabi köyünün 3-4 km güney } \\
\text { batısı }\end{array}$ & 09.07.2019 & $1049 \mathrm{~m}$ & $\begin{array}{l}40^{\circ} 3 ' 30.50^{\prime \prime K} \\
43^{\circ} 44^{\prime} 33.85^{\prime \prime D}\end{array}$ \\
\hline TR19-12 & $\begin{array}{l}\text { Iğdır, Aralık, Ramazankent köyünün 1-2km } \\
\text { güneyi }\end{array}$ & 10.07.2019 & $821 \mathrm{~m}$ & $\begin{array}{l}39^{\circ} 57^{\prime} 5.85^{\prime \prime} \mathrm{K} \\
44^{\circ} 27^{\prime} 24.80^{\prime \prime} \mathrm{D}\end{array}$ \\
\hline TR19-13 & Iğdır, Çalpala köyü & 15.07.2019 & $895 \mathrm{~m}$ & $\begin{array}{l}40^{\circ} 1 ' 29.25 " K \\
43^{\circ} 52^{\prime} 51.77 " \mathrm{D}\end{array}$ \\
\hline TR19-14 & $\begin{array}{l}\text { Iğdır-Kars il sınırı, Donandı köyünün 3-4 km } \\
\text { doğusu }\end{array}$ & 15.07.2019 & $1023 \mathrm{~m}$ & $\begin{array}{l}40^{\circ} 6^{\prime} 37.98 " K \\
43^{\circ} 30^{\prime} 29.03 " \mathrm{D}\end{array}$ \\
\hline TR19-15 & Iğdır, Tuzluca, Gaziler köyü & 23.07.2019 & $1121 \mathrm{~m}$ & $\begin{array}{l}40^{\circ} 5^{\prime} 3.33^{\prime \prime K} \\
43^{\circ} 26^{\prime} 47.45 " \mathrm{D}\end{array}$ \\
\hline
\end{tabular}

Çizelge 2. Aras vadisinde 2019 yılında tespit edilen Cleonini ve Tanymecini türleri ve konukçu bitkiler

\begin{tabular}{ll}
\hline Konukçu Bitkiler & Türler \\
\hline Cirsium arvense (L.) Scop. & Cleonis pigra (Scopoli, 1763) \\
Heliotropium europeum L. & Pachycerus segnis (Germar, 1824) \\
& Entymetopus lineolatus Motschulsky, 1860 \\
Bassia hirsuta (L.) Asch. & Entymetopus limis (Ménétriés, 1849) \\
& Bothynoderes affinis (Schrank, 1781) \\
& Maximus strabus (Gyllenhal, 1834) \\
& Asproparthenis omeri Korotyaev, N. Gültekin \& L. Gültekin, 2020 \\
& Tanymecus tenuis Reitter, 1903 \\
Suaeda altissima (L.) Pall. & Asproparthenis punctiventris (Germar, 1824) \\
& Asproparthenis steveni (Faust, 1892) \\
Suaeda confusa Iljin & Maximus strabus (Gyllenhal,1834) \\
Seidlitzia florida (M. Bieb.) Boiss. & Temnorhinus nasutus (Hochhuth, 1847) \\
Salsola tragus L. & Temnorhinus nasutus (Hochhuth, 1847) \\
Atriplex micrantha Ledeb. & Conorhynchus kindermanni Faust,1904 \\
Tamarix sp. & Temnorhinus hololeucus (Pallas, 1781) \\
Zea mays L. ve Gramineae & Esamus mnischekii (Hochhuth, 1851) \\
& Tanymecus dilaticollis Gyllenhal, 1834 \\
\hline
\end{tabular}




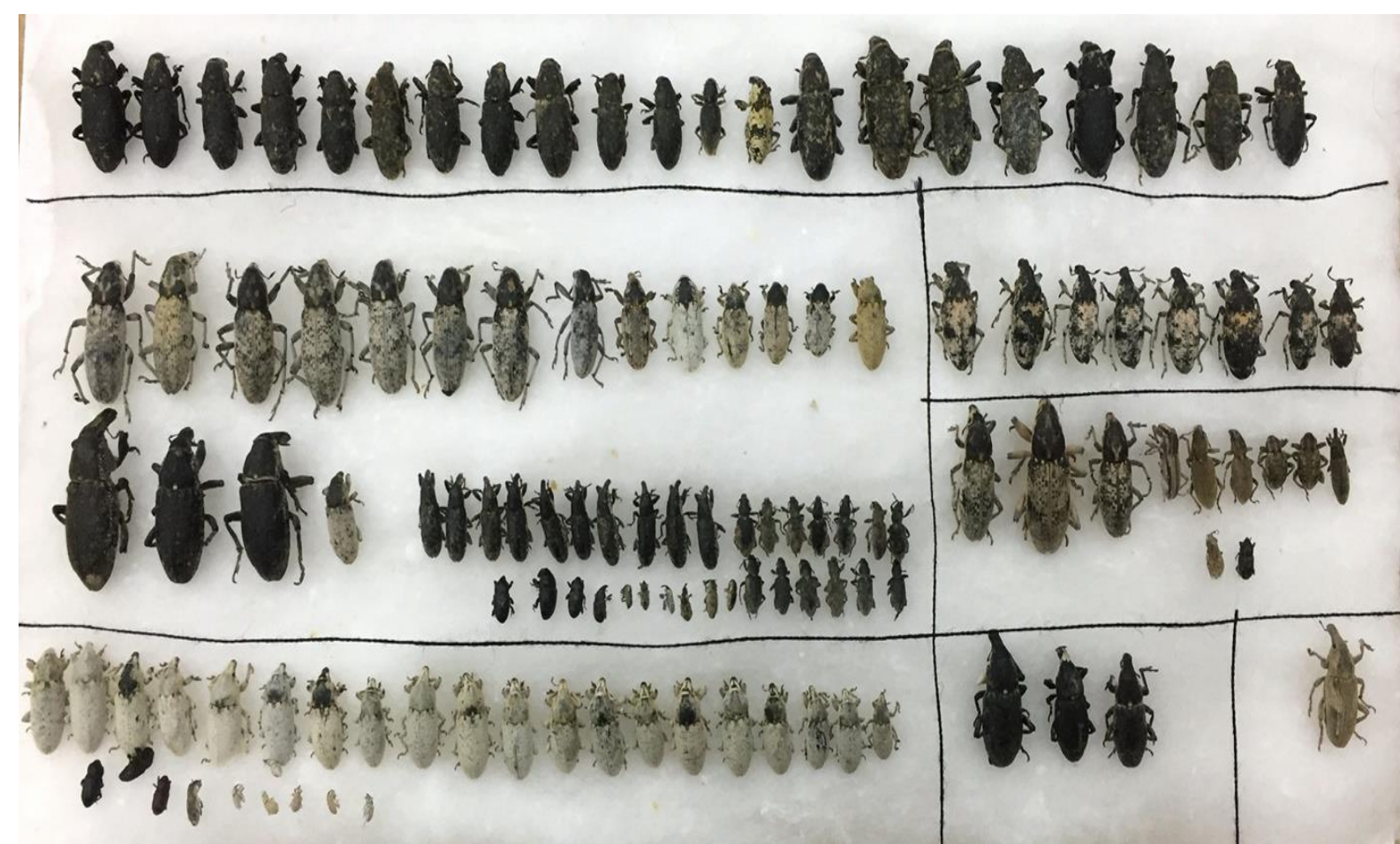

Şekil 1. Koleksiyon muhafaza zarfı ve içerdiği Curculionidae örnekleri (Aras Vadisi)

Yukarıdaki çizelgeden de anlaşılacağı üzere Cleonini türleri çoğunlukla Amaranthaceae (= Chenopodiaceae) bitkilerini, az sayıda da Asteraceae ve Boraginaceae türlerini konukçu bitki olarak tercih etmektedir. Tanymecini türleri ise hem Amaranthaceae hem de Gramineae bitkileri ile beslendiği tespit edilmiştir. Araştırma bölgesinde en çok Bassia hirsuta (L.), Asch., ikinci sırada ise Suaeda altissima (L.) Pall. bitkisini konukçu olarak tercih etmektedir.

Asproparthenis steveni çalışma bölgesinde Suaeda altissima (L.) Pall. (Şekil 2C) bitkisini konukçu olarak tercih etmektedir. Bu bitkiler tuzcul, kumlu, yarı çöl alanlarında özellikle Aralık bölgesinde bu tip habitatlarda hakim türlerden birisidir. Ergin dönem $A$. steveni bireyleri, yer yer ve kümeler halinde gelişen bu bitkilerin arasında, toprak yüzeyinde ve kesekler arasında bulunmakta ve yapraklarla beslenmektedir. Çiftleşme daha çok bitkiler arasındaki açık tuzcul kumlu alanlar üzerinde gerçekleşmektedir. Larva kumlu toprak içerisinde serbest olarak hareket edebilmekte ve konukçusunun kök aksamının dış kısmından beslenmektedir. Aynı alanda toprak içerisinde pupa olmakta (Şekil 2A) ve yeni nesil ergin (Şekil 2B) bireyler topraktan dışarı çıkmaktadır. Elde edilmiş bu biyolojik bulgular literatür için yeni olan ilk bilgilerdir. Transkafkasya, İran, Kazakistan, Türkmenistan ve Türkiye'de yayılış gösteren (Alonso-Zarazaga ve ark., 2017) bu türün konukçu bitkileri olarak Ter-Minassian (1988) Beta vulgaris L., ve Suaeda altissima (L.) Pall.'yI, Fremuth (1987) ise Atriplex tatarica L.'yı bildirmektedir.

Bothynoderes affinis kumlu, tuzcul, çorak eğimli yamaçlar üzerinde yaygın ve dominant bir bitki olan Bassia hirsuta (L.) Asch. yaprakları ile beslendiği, yumurtalarını kök üzerine yapıştırdığı, larvaların bitki kökü içerisinde gelişebilmek için gal şeklinde kökü genişlettiği (Şekil 3A), kök içerisinde beslendiği, aynı yerde pupa ve ergin olduğu, geniş bir çıkış deliği açarak (Şekil 3B) yeni nesil ergin böceğin (Şekil 3C) yaz sonunda buradan çıııp toprağa geçtiği tespit edilmiştir. Bu türün gal yapan (Hoffmann, 1950; Volovnik, 2010) Amaranthaceae bitkileri üzerinde oligofag beslenme özelliğine sahip olduğu bilinmektedir. Konukçu bitki olarak Chenopodium album L., Ch. bothrys L., Salsola kali L., Atriplex patula L., A. tornabeni Tin. (Hoffmann, 1950; Volovnik, 2010), Beta vulgaris L. (Menozzi, 1930) bildirilmektedir. 


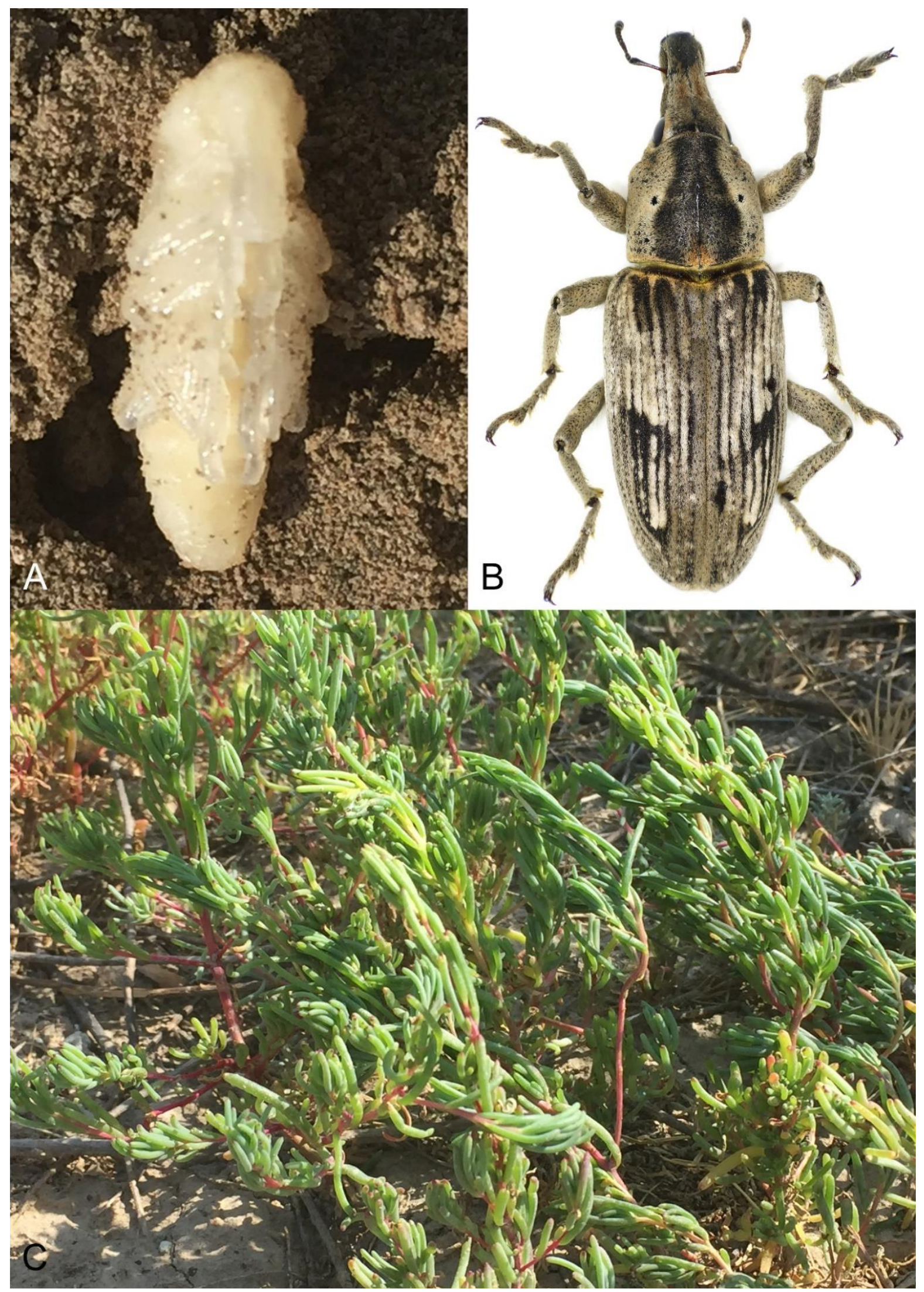

Şekil 2. Asproparthenis steveni (Faust, 1892)'nin bazı biyolojik dönemleri ve konukçu bitki. A, pupa, toprak içerisinde; B, ergin, fotoğraftaki pupanın kültüre alınması ile elde edilmiştir; C, konukçu bitki Suaeda altissima (L.) Pall. 


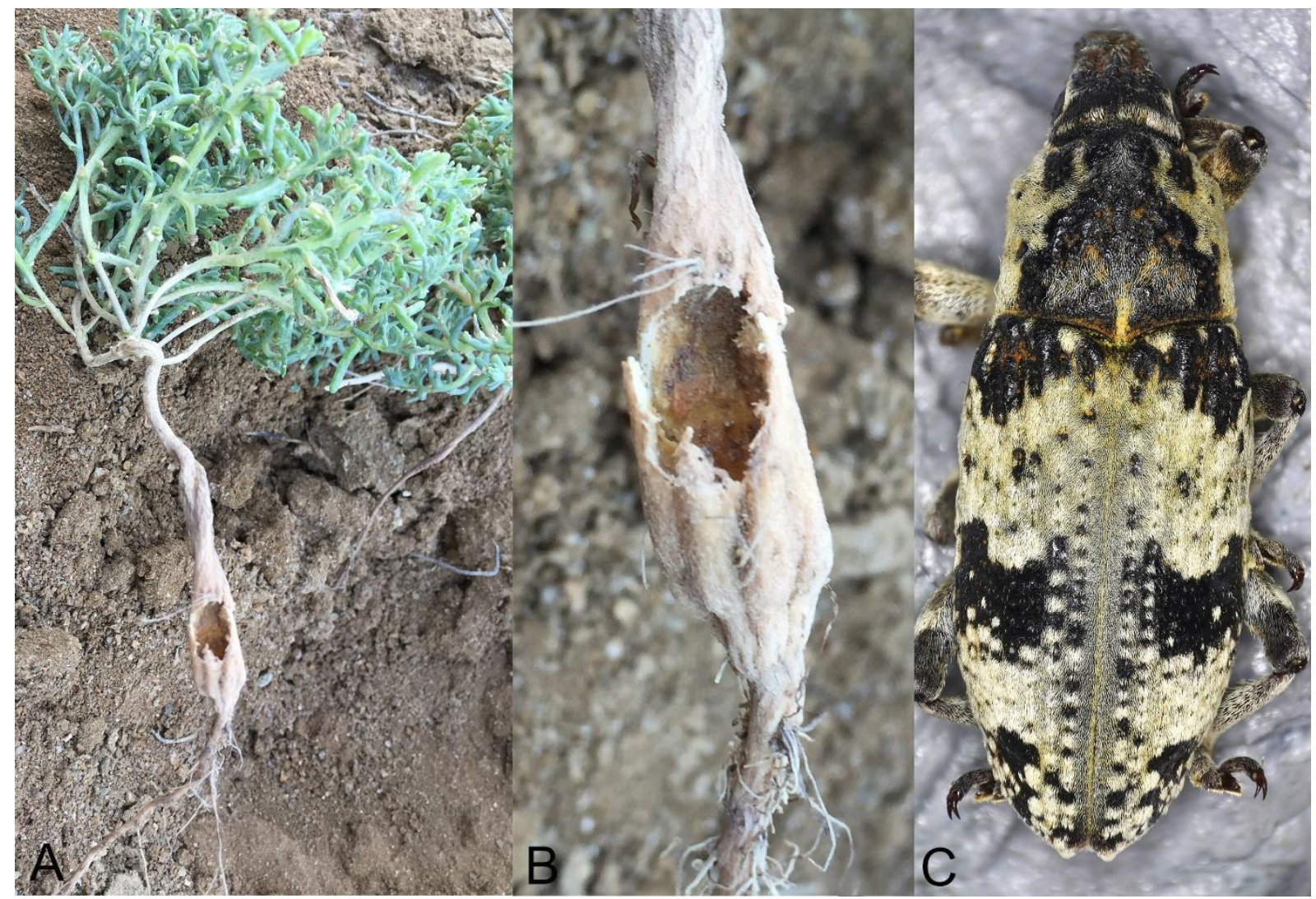

Şekil 3. Bothynoderes affinis (Schrank, 1781)'in konukçu bitkisi Bassia hirsuta (L.) Asch., (A), kökte oluşturduğu gal (B) ve bu gal içerisinden elde edilmiş yeni nesil Bothynoderes affinis ergin dönemi (C).

Entymetopus lineolatus'un konukçu bitkisi ilk olarak bu çalışma ile tespit edilmiş ve Bassia hirsuta (L.) Asch. (Şekil 4A) bu tür için ilk konukçu tespitidir. Böceğin yaşadığı habitat tuzcul, kurak, eğimli, erozyona maruz kalmış bir alandır. Bu alanda hakim bitkiler Halocnemum strobilaceum (Pall.) M. Bieb. ve Bassia hirsuta'dır. Yapılan incelemeler sonucunda konukçu bitkinin yapraklarının toprağa temas ettiği iki noktada toprak içerinde oldukça yüzeysel bir konumda (Şekil 4B), yine topraktan oluşturulmuş ayrı odacıklar içerisinde biri pupa (Şekil 4C), diğeri yeni nesil ergin döneminde $E$. lineolatus bireyleri tespit edilmiştir. Bu biyolojik bulgular literaür için yeni olan bilgilerdir ve ilk kez bu çalışma ile ortaya çıkmıştır.

Entymetopus limis türünün de konukçusunun Bassia hirsuta olduğu Kars, Kağızman'ın 15 km doğusu, Aras Vadisi, 15.VI.1997, 3 कै, 2 \&, B. A. Korotyeav \& M. G. Volkovitsh (Zoological Institute, St. Petersburg) tarafından belirlenmiştir. Bu yeni konukçu bitki tespitinin yanı sıra, Entymetopus limis (Ménétriés, 1849) Türkiye faunası için yeni kayıttır.
Temnorhinus nasutus, erginleri (Şekil 5B) iki farklı lokasyonda iki farklı bitki Seidlitzia florida (Bieb.) Bunge (Şekil 5A) ve Suaeda confusa Iljin (Şekil 5D) ile beslendiği tespit edilmiştir. Erginlerin çoğu Suaeda confusa bitkisi üzerinde beslenirken ya da çiftleşirken bulunmuştur (Şekil 5C). Tespit edilen bu bilgiler $T$. nasutus için ilk biyolojik bulgulardır. Bu çalışmada T. hololeucus erginlerinin çöl habitatında, sıcak temmuz ayında konukçu bitkiye ulaşmak için uçabildiği gözlemlenmiştir. Bu davranış T. hololeucus için ilk kez tespit edilmiştir.

Pachycerus segnis erginleri çalışma bölgesinde Heliotropium europeum L. bitkisinin yaprakları ile beslenmekte, yumurtalarını kökler üzerine yapışkan bir salgı ile tutturmakta, larvalar toprak içerisinde serbest olarak hareket etmekte ve bitkinin kök aksamına zarar vermekte, toprak içinde bir odacık hazırlayarak pupa ve ergin olmaktadır (Gültekin ve ark., 2019). Ayrıca bu türün konukçusu olarak Heliotropium dasycarpum Ledeb. (Ter-Minassian, 1988), Echium vulgare L., Cynoglossum pictum Aiton, C. cheirifolium L. ve Anchusa italica L. belirtilmektedir (Hoffmann, 1950). Bu türün larvalarının $E$. vulgare kökleri içerisinde yaşadığı ve burada şişkinliklere neden olduğu belirtilmektedir (Hoffmann, 1950). 




Şekil 4. Entymetopus lineolatus Motschulsky, 1860'un konukçu bitkisi Bassia hirsuta (L.) Asch. (A), B, habitattoprak içindeki pupa; $C$, toprak odacık içerisinde $E$. lineolatus'un pupa dönemi.

Tanymecus tenuis'in bu çalışmada Bassia hirsuta bitkisi ile beslendiği tespit edilmiştir. Aynı türün Kars ve Iğdır'da yayılış gösterdiği ve Gürcistan'da ise çok yıllık Salsola sp. bitkisi üzerinden toplanmıştır (Korotyaev ve ark., 2015).
Aynı çalışma kapsamında Tanymecus dilaticollis erginleri yabani buğdaygil bitkileri üzerinden toplanmıştır. Bu tür Iğdır ilinde mısır bitkisinin fide döneminde en önemli zararlı olarak belirtilmektedir (Gözüaçık, 2019). 


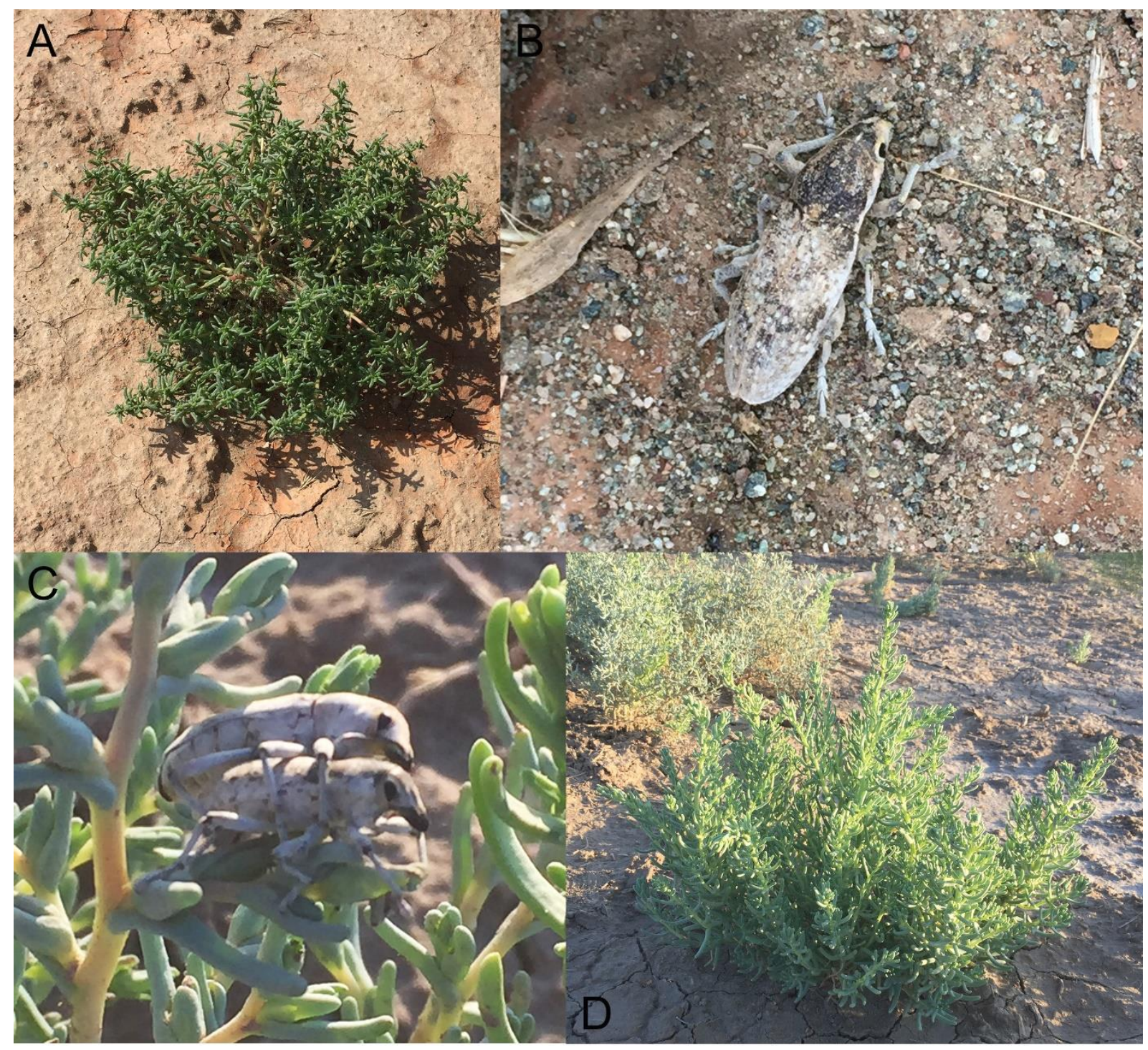

Şekil 5. Temnorhinus nasutus (Hochhuth, 1847) ve konukçu bitkiler. A, Seidlitzia florida (Bieb.) Bunge; B, $T$. nasutus ergin dönem; C, Suaeda confusa Iljin bitkisi üzerinde çiftleşen T. nasutus bireyleri; D, konukçu bitki Suaeda confusa lljin ve tuzcul habitat.

Esamus cinsi ve Esamus mnischekii türü Türkiye faunası için yeni kayıttır. Bir birey "Kars, Kağızman'ın 15 km doğusu, Aras Vadisi, 4009'12" K, 4315'17" D, 1120 m, Tamarix sp., 18.05.2015, 1 (B.A. Korotyaev)" belirtilen lokasyondan toplanmıştır. Bu alan Nitraria schoberi L. ve Tamarix sp. bitkilerinin yayılış gösterdiği tuzcul bir habitattır. Esamus mnischekii ve E. subpilosus Reitter, 1903, birbirine çok benzer türlerdir (Korotyaev, 2018), Trasnkafkasya'nın doğusunda ve Türkmenistan'da yayılış göstermekte (AlonsoZarazaga ve ark., 2017) ve bu zamana kadar Türkiye'de yayılış gösterdiği bilinmemektedir. Esamus mnischekii köken olarak Turan çöl faunasına ait bir türdür ve Aras vadisinde geniş alanları kaplayan çöl habitatına ait halofit bitkilerle özdeşleşen fauna elemanlarından biri olduğu bu çalışma ile ortaya çıkmıştır.

\section{Sonuç ve Öneriler}

Sonuç olarak bu çalışma ile, Aras vadisinde yayılış gösteren 12 Cleonini ve 3 Tanymecini türü ile ilgili olarak biyolojik, biyocoğrafik ve konukçu bitkilerle ait yeni bulgular sunulmuştur. En ilginç biyolojik bulgulardan birisi Temnorhinus hololeucus'un doğada uçma davranışının gözlemlenmesidir. Entymetopus lineolatus'un pupa dönemi ve konukçu bitkisi ilk kez bu araştırma ile tespit edilmiş olmasıdır. Ayrıca, Entymetopus limis, Esamus Chevrolat, 1880 cinsi ve Esamus mnischekii (Hochhuth, 1851) Türkiye faunası için yeni kayıttır.

Teşekkür: Bu çalışma Iğdır Üniversitesi Bilimsel Araştırma Projeleri Birimi (BAP) 2019-FBE-A14 numaralı proje ile desteklenmiştir. Konukçu bitkilerin teşhisi için Prof. Dr. Vladimir I. Dorofeyev (Komarov Botanical Institute, St. Petersburg)'e teşekkür ederiz. Bu çalışma, Russian Foundation for 
Basic Research (RFBR) (Proje No 14-04-91373) ve TÜBITAK (Proje No 2130014) projeleri tarafından da kısmı olarak desteklenmiştir. Ayrıca, B.A. Korotyaev, ZIN collection State Program (Proje no AAAA-A19-119020690082-8), RFBR (Proje No 1904-00565 A) ve RFBR (Proje No 18-05-00557 A) projeleri ile desteklenmiştir.

Çıkar Çatışması Beyanı: Makale yazarları aralarında herhangi bir çıkar çatışması olmadığını beyan ederler.

Araştırmacıların Katkı Oranı Beyan Özeti: Yazarlar makaleye eşit oranda katkı sağlamış olduklarını beyan ederler.

\section{Kaynaklar}

Alonso-Zarazaga, M. A., Barrios, H., Borovec, R., Bouchard, P., Caldara, R., Colonnelli, E., Gültekin, L., Hlaváč, P., Korotyaev, B., Lyal, C. H. C., Machado A., Meregalli, M., Pierotti, H., Ren, L., Sánchez-Ruiz, M., Sforzi, A., Silfverberg, H., Skuhrovec, J., Trýzna, M., Velázquez de Castro, A. J., Yunakov, N. N. 2017. Cooperative Catalogue of Palaearctic Coleoptera Curculionoidea. Monografías electrónicas SEA, 8: 729 pp.

Anderson, R. S. 1987. Systematics, phylogeny and biogeography of New World weevils traditionally of the tribe Cleonini (Coleoptera: Curculionidae; Cleoninae). Quaestiones Entomologicae, 23: 431-709.

Arzanov, Yu. G., Grebennikov, V. V. 2017. Cleonini (Coleoptera: Curculionidae: Lixinae) are monophyletic and flightless: tribe overview, rampant adult homoplasy and illustrated global diversity. Zootaxa, 4329 (1): 1-63.

Davidian, G. E. 2019. Tanymecus dilaticollis Gyll. Maize Leaf Weevil (Southern Gray Weevil). Interactive Agricultural Ecological Atlas of Russia and Neigboring Countries. Economic Plants and their Diseases, Pests and Weeds. http://www.agroatlas.ru/en/content/pests/ Tanymecus_dilaticollis/index.html

EPPO, 2015. Global Database - European and Mediterranean Plant Protection Organization. Curculionidae. Available from: http://gd.eppo.int/taxon/1CURCF (accessed 15 November 2017)

Fremuth, J. 1987. Ergebnisse der Tschechoslowakisch-Iranischen entomologischen expeditionen nach dem Iran 1970, 1973 und 1977 Coleoptera, Curculionidae; 1. Teil: Cleoninae. Acta Entomologica Musei Nationalis Pragae, 42: 321-348.
Gözüaçık, C. 2019. Iğdır ili mısır alanlarında Mısır maymuncuğu, Tanymecus dilaticollis Gyllenhal (Coleoptera: Curculionidae)'in yayılışı ve zararı durumunun belirlenmesi. 6 . Ulusararası Mesleki ve Teknik Bilimler Kongresi, 11-12 Nisan 2019, Iğdır, s. 332337.

Güllü, M., Sertkaya, E. 2011. Çukurova'da mısır bitkisinde zararlı yeni bir böcek: Mısır maymuncuğu, Tanymecus dilaticollis Gyllenhal (Coleoptera: Curculionidae). Türkiye IV. Bitki Koruma Kongresi Bildirileri, 28-30 Haziran 2011, Kahramanmaraş, s. 302.

Gültekin, N. 2018. Anadolu Cleonini (Coleoptera: Curculionidae) Türleri Üzerinde Faunistik ve Sistematik Araştırmalar. Atatürk Üniversitesi, Fen Bilimleri Enstitüsü, Biyoloji Anabilim Dalı, Doktora Tezi, $162 \mathrm{~s}$.

Gültekin, N., Gözüaçık, C., Aykut E. 2019. Aras Vadisinde Heliotropium europaeum L. yabancl otu ile beslenen Pachycerus segnis (Germar, 1823) (Coleoptera: Curculionidae) üzerinde biyolojik gözlemler. Muş Ovası Uluslararası Tarım Kongresi, 24-27 Eylül 2019, Muş, s. 199-206.

Hoffmann, A. 1950. Faune de France 52. Coléoptères curculionides (Première partie). Paris: Lechevalier, $486 \mathrm{pp}$.

Korotyaev, B. A. 2018. New records of weevils of the subtribe Tanymecina (Coleoptera, Curculionidae: Entiminae) collected by O. N. Kabakov in Afghanistan. Entomological Review, 98 (8): 1088-1090.

Korotyaev, B. A. 2000. On unusually high diversity of rhynchophorous beetles (Coleoptera: Curculionoidea) in steppe communities of the North Caucasus. Zoologicheskiy Zhurnal, 79 (2): 242-246. (In Russian); English translation: Entomological Review, 80(8): 1022-1026.

Korotyaev, B. A., Davidian, G. E., Gültekin, L. 2015. Contribution to the weevil fauna (Coleoptera, Curculionoidea) of Turkey. Entomologicheskoe Obozrenie, 94 (1): 103111. (In Russian); [English translation: Entomological Review 95 (8): 1099-1105 (2015)].

Korotyaev B. A., Gültekin N., Gültekin L. 2020. A new species Asproparthenis omeri sp. nov. (Coleoptera: Curculionidae: Lixinae) from the Aras valley in northeastern Turkey. Journal of Insect Biodiversity, 17 (1): 12-27.

Lemic, D., Benítez, H. A., Püschel, T. A., Gašpari, H. V., Šatvar, M., Bažok, R. 2016. Ecological morphology of the sugar beet weevil Croatian populations: Evaluating the role of 
environmental conditions on body shape. Zoologischer Anzeiger, 260: 25-32.

Lukjanovitsh, F. K. 1958. On the biology, geographic distribution, and systematics of species of the subgenus Bothynoderes s. str. (Coleoptera:

Curculionidae). Entomologicheskoe Obozrenie, 37 (1): 105123. (In Russian)

Marshall, G. A. K., Lodos, N. 1979. [new taxon]. In: Lodos N. A short note about Megamecus shevketi Marshall; a name used longtime as a nomen nudum (Coleoptera: Curculionidae - Tanymecinae). Türkiye Bitki Koruma Dergisi, 3: 217-223.

Menozzi, C. 1930. Insetti dannosi alla barbabietola osservati durante la campagna 1929. (Osservazioni ed appunti preliminari). L'Industria Saccarifera Italiana, 23 (1, 2, 4): 4-25, 57-73, 151-176.

Meregalli, M., Fremuth, J. 2013. Subfamily Lixinae. Tribe Cleonini. pp. 437-456. In: Löbl I. \& Smetana A. (eds.): Catalogue of Palaearctic Coleoptera. Volume 8. Curculionoidea II. Brill, Leiden, $700 \mathrm{pp}$.

Meregalli, M. 2014. Lixinae Schoenherr, 1823. In: Leschen, R. A. B. \& Beutel, R. G. (Eds.), Handbook of Zoology, Arthropoda: Insecta: Coleoptera. Volume 3: Morphology and Systematics (Phytophaga). Walter de Gruyter, Berlin, pp. 523-529.

Oberprieler, R. G., Marvaldi, A. E., Anderson, R. S. 2007. Weevils, weevils, weevils everywhere. Zootaxa, 1668: 491-520.

Stejskal, R., Trnka, F. 2014. Curculionidae: Lixinae. Icones insectorum Europae centralis. Folia Heyrovskyana, 20: 1-17.

Stinson, C. S. A., Schroeder, D., Marquardt, K. 1994. Investigations on Cyphocleonus achates (Fahr.) (Col., Curculionidae), a potential biological control agent of spotted knapweed (Centaurea maculosa Lam.) and diffuse knapweed (C. diffusa Lam.) Compositae in North America. Journal of Applied Entomology, 117: 35-50.

Story, J. M., Callan, N. W., Corn, J. G., White, L. J. 2006. Decline of spotted knapweed density at two sites in western Montana with large populations of the introduced root weevil, Cyphocleonus achates (Fahraeus). Biological Control, 38: 227-232.

Ter-Minassian, M. E. 1958. A review of species of the subgenus Bothynoderes Germ. s. str. (Coleoptera: Curculionidae). Entomologicheskoe Obozrenie, 37 (1): 124131. (In Russian)

Ter-Minassian, M. E. 1988. Weevils of the subfamily Cleoninae of the fauna of USSR: tribe Cleonini. Opredeliteli po faune SSSR, izdavaemye Zoologicheskim Institutom Akademii Nauk SSSR, 155: 1-235. (In Russian)

Tóth, M., Furlan, L., Campagna, G. 2007. Attractant for the sugar-beet weevil Conorrhynchus (Cleonus) mendicus (Col.: Curculionidae). Journal of Applied Entomology, 131: 569572.

Trnka, F., Stejskal, R., Skuhrovec, J. 2015. Biology and morphology of immature stages of Adosomus roridus (Coleoptera: Curculionidae: Lixinae). Zootaxa, 4021 (3): 433-446.

Volovnik, S. V. 2010. Lixine weevils (Coleoptera, Curculionidae) as gall formers. Zoologicheskiy Zhurnal, 2010, 89(7): 828833. (In Russian). [English translation: Entomological Review, 90 (5): 585-590]. 